\title{
Asbestos and public health policy in Brazil
}

A hundred years since initial observations on the pathogenicity of asbestos fibers, there is now consensus that the wide range of their adverse effects (described consistently since 1906) constitutes a serious public health problem. The burden of disease, disability, and early death attributable to occupational and/or environmental exposure to asbestos fibers (in all their forms) has been characterized unequivocally and bears the mark of "avoidability", since many substitute fibers have already been widely tested and have proven far safer when compared to asbestos with its pathogenicity and carcinogenicity. More than 50 countries worldwide have prohibited or banned all forms of asbestos. The vast majority of Brazilian civil society is also demanding such a ban, but has been ignored by government, which stubbornly tramples over the "precautionary principle" and a huge range of citizens' rights.

In fact, all the disease entities described as associated with asbestos exposure - like asbestosis and lung cancer - have been known in Brazil, some for more than 50 years. Other diseases, like malignant mesothelioma, which previously appeared to be more rare, have now become increasingly common, due both to improved diagnosis and the long latency period (25 to 35 years) usually required by these tumors to develop following initial exposure.

Since Brazil is a major producer and consumer of asbestos (in the form of chrysotile or "white asbestos"), which is mined, marketed, processed into various products, or exported from the deposits in Minaçu, Goiás State, one would expect the issue to be treated in such a way as to prioritize environmental protection, especially safeguarding the population's health, including the health of workers throughout the entire industrial chain and all the way to consumers, namely millions of Brazilians.

Despite the wealth of evidence on the hazards of asbestos exposure, the issue has been treated in Brazil with brazen, even criminal shortsightedness, marked by negligence and omission on the part of the Executive, Legislative, and Judiciary Branches. Asbestos-related economic interests (the privilege of a few companies) have prevailed to this day. The sophisms "safe use" and "controlled use" have persistently outweighed public health policy.

Brazilian public policy in this area is still shackled by the obsolete National Act 9,055/95 and Decree 2,350/97. The National Supreme Court has ruled that State laws banning asbestos within their jurisdictions are unconstitutional. An Inter-Ministerial Commission created in 2004 advised the Federal government of the severe risks involved in a permissive approach to asbestos. However, once again the force of economic power and lobbies prevailed in the Federal government, and the Commission's report was ignored and shelved. Ministry of Health Ruling GM 1,851/2006 regulating Decree 2,350/97 in relation to workers' health surveillance procedures was suspended by the Supreme Court in response to a challenge by a handful of companies.

A definitive ban on the mining, marketing, processing, use, and export of these carcinogenic fibers is the only honest alternative, from the Constitutional perspective of the right to an "ecologically balanced environment" (Article 235), the right to health (Article 196), and consumer defense (Act 8,078/90).

How long will negligence and omission be tolerated in Brazil to the benefit of powerful economic interests? 